\title{
UMA CÉLULA SIMPLES PARA ADAPTAÇÃO DE ELETRODOS SELETIVOS COMERCIAIS EM SISTEMAS DE ANÁLISES EM FLUXO
}

\author{
Maria Angélica Bonadiman Marin \\ Centro Federal de Educação Tecnológica do Paraná - CEFET - CP 391 - 85884-000 - Medianeira - PR \\ Edgard Moreira Ganzarolli, Roldão Rooseveld Urzêdo de Queiróz e Ivan Gonçalves de Souza \\ Departamento de Química - CFM - Universidade Federal de Santa Catarina - 88040 - 900 - Florianópolis - SC
}

Recebido em 15/7/97; aceito em 24/3/98

\begin{abstract}
A SIMPLE CELL FOR ASSEMBLING COMMERCIAL ION-SELECTIVE ELECTRODES IN CONTINUOUS FLOW ANALYZERS. A simple flow cell for potentiometric detection is described. It was assembled by making use of two perspex pieces fixed together by means of four screws, and allow the connection of plane membrane conventional electrodes to flow system. Details about its construction are presented. The device performance was evaluated by making use of a cyanide ion-selective electrode. The relative standard deviation was about $0.5 \%$ with a detection limit of $8.0 \times 10^{-6}$ mol $\mathrm{CN}^{-} \mathrm{dm}^{-3}$. Under experimental conditions, the linear range was $10^{-5}$ to10 $^{-2} \mathrm{~mol} \mathrm{dm}^{-3}$.
\end{abstract}

Keywords: flow cell; potentiometric detector; continuous flow analysis.

\section{INTRODUÇÃO}

Vários arranjos de eletrodos, ou modelos de células de detecção potenciométrica para sistemas de análise em fluxo contínuo (AFC), ou de análise por injeção em fluxo (FIA), têm sido descritos ${ }^{1-3}$. Algumas são adaptações que possibilitam o uso de eletrodos comerciais em sistemas de fluxo ${ }^{4,5}$

Uma das primeiras adaptações de um eletrodo íon-seletivo (EIS) comercial para sistemas em fluxo foi feita através da configuração tipo cascata ${ }^{2}$. Este tipo de configuração apresentava problemas relacionados com sua instabilidade mecânica.

Atualmente existe uma tendência em se empregar eletrodos de forma tubular para análises em fluxo ${ }^{6}$. A forma destes eletrodos possibilita a construção de detectores com volume morto muito pequeno. Contudo, muitos laboratórios não dispõem de eletrodos tubulares ou qualquer outro tipo específico para análises em fluxo, e sim de eletrodos seletivos comerciais destinados a medidas em situação estacionária. Este problema pode ser contornado através da confecção de uma célula detectora para adaptação destes eletrodos a sistemas em fluxo. Neste trabalho, é descrita uma célula de fluxo simples e de baixo custo, construída para esta finalidade e que pode ser adaptada para eletrodos onde a superfície sensora é plana. Utilizou-se um eletrodo para cianeto de membrana sólida heterogênea para avaliação do desempenho desta célula.

\section{PARTE EXPERIMENTAL}

\section{Sistema de fluxo}

A figura 1 mostra o sistema montado para se testar o desempenho da célula detectora. Ele é composto basicamente por uma bomba peristáltica de quatro canais (Ismatec modelo 07341-15), injetor proporcional, tubos de Tygon ${ }^{\circledR}($ d.i. $=1,65$ e $2,06 \mathrm{~mm}$ ), tubos de polietileno $($ d.i. $=0,8 \mathrm{~mm}$ ), célula do eletrodo indicador, eletrodo indicador para cianeto (Orion modelo 94-06BN), eletrodo de referência $\mathrm{Ag} / \mathrm{AgCl}$ com dupla junção (Cole Parmer modelo 5990-64), potenciômetro (Orion modelo 720A) e registrador (ECB modelo RB400).

Para injeção das soluções padrão, utilizou-se um injetor proporcional $^{7}$ com alça de amostragem de $10 \mathrm{~cm}$ e d.i. $=0,8 \mathrm{~mm}$.

$\mathrm{O}$ eletrodo de referência ficou mergulhado no frasco de descarte, juntamente com o tubo de polietileno ligado à saída da célula contendo o eletrodo indicador. A solução contida neste tubo possibilitou o contato elétrico entre o eletrodo indicador e referência.

O sistema de detecção indicador/referência foi conectado ao potenciômetro e este ao registrador.

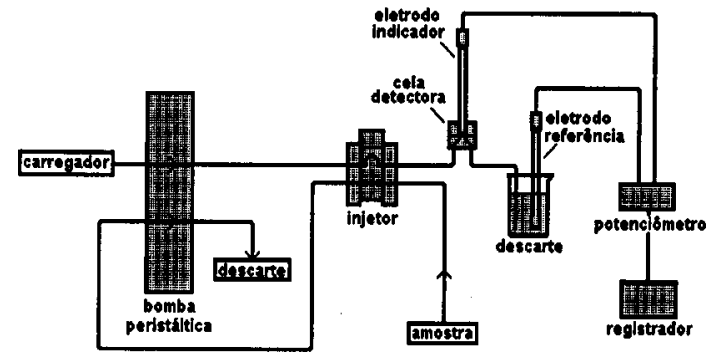

Figura 1. Sistema de fluxo para determinação potenciométrica de cianeto.

\section{Célula de fluxo}

A célula de fluxo é composta basicamente por duas peças de acrílico unidas entre si por quatro parafusos (Fig. 2).

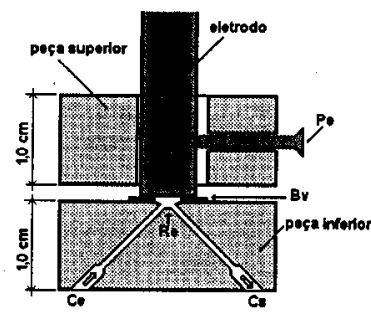

a

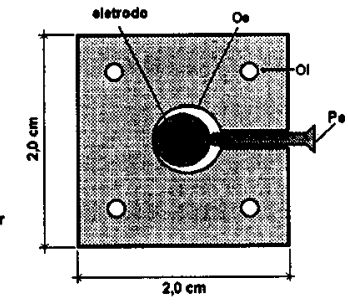

b
Figura 2. (a) Corte longitudinal, Bv = borracha de vedação, Ce = canal de entrada, $C s=$ canal de saída, $P e=$ parafuso do eletrodo, $R e$ $=$ rebaixo; $(\boldsymbol{b})$ corte transversal da peça superior, Oe $=$ orifício do eletrodo, $\mathrm{Ol}=$ orifício lateral, $\mathrm{Pe}=$ parafuso do eletrodo.

A peça superior possui quatro orifícios laterais (Ol) com diâmetro igual a $0,3 \mathrm{~cm}$ para os parafusos de fixação da célula 
(não mostrados na fig. 2), um orifício central com diâmetro igual a $1,5 \mathrm{~cm}$ para passagem do eletrodo e um orifício lateral com rosca, para o parafuso de fixação do eletrodo $(\mathbf{P e})$. O diâmetro interno do orifício central foi definido de forma a permitir que o eletrodo se encaixasse na célula.

A peça inferior possui também os quatro orifícios laterais (Ol) alinhados com os mesmos da peça superior. Um rebaixo (Re) no centro de sua superfície interna com diâmetro de 3 $\mathrm{mm}$ e profundidade de $2 \mathrm{~mm}$ atua como câmara de contato entre a solução e a superfície sensível do eletrodo. Esta câmara fica conectada a dois canais transversais, ambos com diâmetro interno de $1 \mathrm{~mm}$, sendo um para entrada $(\mathbf{C e})$ e outro para a saída (Cs) da solução.

$\mathrm{Na}$ montagem da célula, um anel de borracha (Bv, fig. 2a) de espessura igual a $0,5 \mathrm{~mm}$ foi colocado entre a superfície sensível do eletrodo e a peça inferior. Este anel apresenta um diâmetro de $10 \mathrm{~mm}$ e um orifício no centro com diâmetro igual ao do rebaixo $(3 \mathrm{~mm})$.

\section{Operação}

Utilizou-se como transportador uma solução $0,1 \mathrm{~mol} \mathrm{dm}^{-3} \mathrm{de}$ nitrato de potássio e soluções padrão de cianeto nas concentrações de: $1,0 \times 10^{-5} ; 1,0 \times 10^{-4} ; 1,0 \times 10^{-3}$ e $1,0 \times 10^{-2} \mathrm{~mol} \mathrm{dm}^{-3}$. As injeções das soluções-padrão foram realizadas em triplicata para se avaliar a repetibilidade das medidas. As médias de cada triplicata foram utilizadas para se levantar uma curva de calibração e assim determinar a equação da reta e seu coeficiente de correlação.

Utilizou-se vazão do transportador igual a $4,3 \mathrm{~mL} \mathrm{~min}^{-1} \mathrm{e}$ taxa de aspiração da amostra igual a $2,8 \mathrm{~mL} \mathrm{~min}^{-1}$.

No frasco de descarte contendo o eletrodo de referência colocou-se uma solução $1,0 \mathrm{~mol} \mathrm{dm}^{-3}$ de hidróxido de sódio como forma de se garantir que o cianeto permanecesse na forma de $\mathrm{CN}^{-}$.

\section{RESULTADOS E DISCUSSÃO}

A figura 3 apresenta o conjunto de picos obtidos com as soluções-padrão injetadas. Pode se verificar pelas triplicatas mostradas no fiagrama que as medidas apresentam boa repetibilidade (desvio padrão relativo em torno de $0,5 \%$ ).

A regressão linear dos pontos experimentais apresentou a seguinte equação: $\mathrm{E}=-452,0-59,6 \cdot \log \mathrm{C}$, onde $\mathrm{E}=$ potencial do eletrodo indicador em relação ao referência $(\mathrm{mV})$ e $\mathrm{C}=$ concentração molar de $\mathrm{CN}^{-}$. O coeficiente de correlação da curva analítica foi de 0,998 , demonstrando assim, uma boa lineariadade de resposta na faixa de concentração estudada $\left(10^{-5}-10^{-2} \mathrm{~mol} \mathrm{dm}^{-3}\right)$.

O limite de detecção ficou em torno de $8,0 \times 10^{-6} \mathrm{~mol} \mathrm{dm}^{-3}$ de cianeto.

Problemas relacionados com a dispersão da zona de amostra geralmente ocorrem em células na configuração "wall-jet" devido ao seu volume morto relativamente grande ${ }^{8}$. Outro problema que pode ocorrer neste tipo de configuração é retenção de bolhas de ar no interior da célula.

O projeto da célula proposta reduz a possibilidade de retenção de bolhas de ar na superfície sensível do eletrodo indicador. Seu pequeno volume morto, aliado ao ângulo de $90^{\circ}$ entre

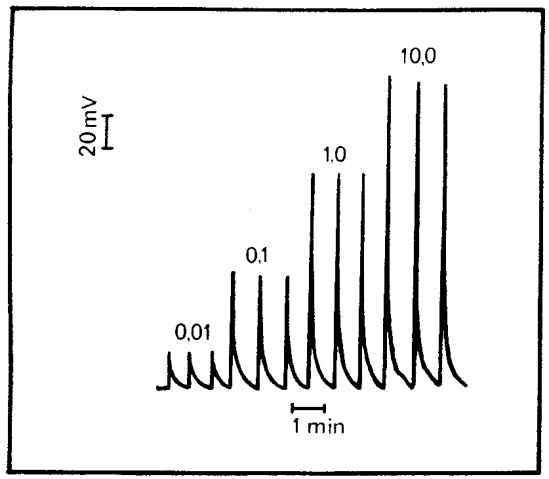

Figura 3. Picos obtidos injetando-se em triplicata $(50 \mu \mathrm{L})$ as soluções - padrão de cianeto 0,$01 ; 0,1 ; 1,0$ e $10,0 \mathrm{mmol} \mathrm{dm}^{-3}$. Solução transportadora de nitrato de potássio em $\mathrm{pH}$ 11,5. Potencial em $\mathrm{mV}$ do eletrodo indicador versus referência de $\mathrm{Ag} / \mathrm{AgCl}$.

os canais de entrada (Ce) e saída (Cs), possibilitam que o próprio fluxo transportador se encarrege de arrastá-las sem diminuir a sensibilidade das medidas.

Assim, recomenda-se este modelo de célula para métodos analíticos em fluxo, onde a utilização de eletrodos íon-seletivos e a sensibilidade constituem-se em parâmetros críticos.

Quando bem ajustada esta célula não apresenta vazamento de solução, fator indispensável no caso de amostras tóxicas como o cianeto.

Esta célula pode ser construída usando-se apenas ferramentas comuns como furadeira, lima, serra, etc.

Uma das maiores vantagens apresentada pela célula proposta, é o fato desta permitir a adaptação de eletrodos destinados a análise em situação estacionária para sistemas em fluxo. Desta forma estes eletrodos podem ser utilizados nas duas condições. Já eletrodos em configuração tubular por exemplo, não podem ser utilizados para determinações em situação estacionária.

\section{AGRADECIMENTOS}

Os autores agradecem ao CNPq, CAPES e FINEP pelo apoio financeiro.

\section{REFERÊNCIAS}

1. Blaedel, W. J.; Olson, C. L.; Sharma, L. R.; Anal. Chem. 1963, 35, 2100 .

2. Ruzicka, J.; Hansen, E. H.; Zagatto, E. A. G.; Anal. Chim. Acta. 1977, 88, 1

3. Alegret, S.; Alonso, J.; Bartrolí, J.; Machado, A, A. S. C.; Lima, J. L. F. C.; Paulís, J. M.; Quim. Anal. 1987, 6, 278.

4. Bartroli, J.; Alerm, L.; Anal. Chim. Acta. 1992, 269, 29.

5. Peták, P.; Stulík, K.; Anal. Chim. Acta. 1986, 185, 171.

6. Reis, B. F.; Quim. Nova 1996, 19, 51.

7. Zagatto, E. A. G.; Krug, F. J.; Bergamin Fo, H.; Joergensen, S. S.; Reis, B. F.; Anal. Chim. Acta 1979, 104,279

8. Douglas, J. G.; Anal. Chem. 1989, 61, 922. 